\title{
¿CÓMO SE DEFINE EL LIDERAZGO EN LA DEFENSA EUROPEA? UN ANÁLISIS fsQCA
}

\section{How is Leadership Defined in the Politics of European Defence? An fsQCA Analysis}

\author{
GUILLEM COLOM PIELLA \\ Universidad Pablo de Olavide \\ Universidad Autónoma de Chile \\ gcolpie@upo.es
}

\author{
IVÁN MEDINA IBORRA \\ Universidad de Valencia \\ ivan.medina@uv.es
}

\section{JOSÉ ANTONIO PEÑA RAMOS \\ Universidad Pablo de Olavide \\ Universidad Autónoma de Chile \\ japer@upo.es}

Cómo citar/Citation

Colom Piella, G., Medina Iborra, I. y Peña Ramos, J. A. (2017).

¿Cómo se define el liderazgo en la defensa europea? Un análisis fsQCA.

Revista de Estudios Políticos, 175, 111 -144.

doi: http://dx.doi.org/10.18042/cepc/rep.175.03

\section{Resumen}

El artículo aborda la cuestión del liderazgo nacional en la defensa europea para determinar el peso relativo de distintos factores en su ejercicio y las razones por las cuales unos países parecen más dispuestos que otros a contribuir a la Política Común de Seguridad y Defensa. Para ello, se empiezan discutiendo las principales aportaciones de los enfoques (neo)realista y constructivista al liderazgo europeo en defensa. Posteriormente, se repasa la evolución de esta política, destacando sus avances y 
retrocesos. A continuación, se identifican los factores que caracterizan esta dimensión y que sirven como base para construir las condiciones del análisis fsQCA que se utilizará para estudiar el liderazgo en la defensa europea, examinando separadamente las condiciones necesarias y suficientes para los países líderes y para los países que no muestran tal liderazgo.

\title{
Palabras clave
}

Liderazgo; defensa; Unión Europea; realismo; constructivismo.

\begin{abstract}
The paper addresses the issue of national leadership in the politics of European defence, in order to determine the relative value of different factors in the exercise of leadership, and the reasons why some countries are more willing than others to contribute to the development of the EU's Common Security and Defence Policy. The article starts by discussing the main contributions of the (neo)realist and constructivist approaches to European leadership on defence. It then highlights the process of development of EU defence policy and its setbacks. Leadership factors that characterize this development process are identified and employed to construct a fsQCA analysis, which assesses the leadership shown by different European countries. This analysis examines the necessary and the sufficient conditions characteristic both of leading countries and of those countries that do not show such leadership.
\end{abstract}

\section{Keywords}

Leadership; defence; European Union; realism; constructivism. 


\section{SUMARIO}

I. INTRODUCCIÓN. II. LIDERAZGO Y SEGUIDISMO EN LA PCSD. III. REALISMO Y CONSTRUCTIVISMO: DIFERENTES FORMAS DE ENTENDER EL LIDERAZGO. IV. LOS FACTORES QUE IMPULSAN EL DESARROLLO DE LA PCSD. V. METODOLOGÍA, CONSTRUCCIÓN DEL OUTCOME Y SELECCIÓN DE CONDICIONES: 1. La técnica fsQCA. 2. Construcción y calibración del outcome (países líderes en defensa). 3. Selección y calibración de las condiciones. VI. RESULTADOS: 1. Condiciones necesarias y suficientes para los países líderes. 2. Condiciones necesarias y suficientes para países que no muestran liderazgo. VII. CONCLUSIONES. BIBLIOGRAFía.

\section{INTRODUCCIÓN}

¿Qué necesita un Estado para liderar la configuración de la defensa europea? ¿Por qué algunos países parecen más dispuestos a contribuir al desarrollo de la Política Común de Seguridad y Defensa (PCSD) que otros? ¿Existen elementos objetivos que expliquen las contribuciones nacionales a la PCSD? Las respuestas a estas preguntas abarcan desde consideraciones políticas como los antecedentes históricos, situación geopolítica, preferencias estratégicas o intereses militares, cuestiones objetivas como los gastos en defensa, la entidad, orientación y medios materiales de los ejércitos o las capacidades industriales nacionales hasta otros elementos subjetivos vinculados con la percepción de los riesgos o las experiencias pasadas que determinan las contribuciones nacionales en el avance de la defensa europea.

Precisamente, este artículo pretende resolver estas cuestiones y conocer el peso relativo que poseen distintos factores — presupuesto de defensa, tamaño y catálogo de capacidades de los ejércitos, cultura estratégica, medios industriales, colaboración en proyectos armamentísticos conjuntos o participación en iniciativas militares - en el ejercicio del liderazgo europeo en defensa y determinar las razones por las cuales unos países parecen más dispuestos que otros a contribuir al desarrollo de la PCSD.

Para lograr este objetivo, se realizará un Análisis Cualitativo Comparado (Qualitative Comparative Analysis - QCA-) en su vertiente fuzzy sets (fsQCA) para identificar las condiciones necesarias determinantes para explicar el liderazgo en defensa entre los países de la Unión Europea (UE). Además, 
esta metodología permite capturar una cierta variabilidad o equifinalidad en la configuración de condiciones suficientes que pueden motivar que un país sea considerado líder en esta materia. Igualmente, se estudian las condiciones necesarias y suficientes de los países que no lideran la PCSD dado que el análisis de los dos escenarios de ocurrencia del outcome - presencia y ausenciaenriquece nuestro análisis.

Para ello, el artículo propone una clasificación de países de acuerdo a su contribución a varios aspectos que la literatura identifica como relevantes para explicar el liderazgo militar. Nos encontramos con la necesidad de proponer una definición amplia, pues se tiende a clasificar los países dependiendo de su liderazgo político, cultura estratégica, entidad de sus ejércitos, capacidad de despliegue y sostenimiento de sus fuerzas o la contribución a proyectos multinacionales. Nuestra propuesta pretende establecer un liderazgo transversal a partir de la suma de cada uno de estos índices. El ranking resultante, que será calibrado para reflejar variación entre propensión o ausencia de liderazgo, será el outcome de nuestro análisis.

Teniendo en cuenta estos elementos, el artículo comienza repasando la evolución de la dimensión europea de seguridad y defensa. Seguidamente, se discuten las principales aportaciones de los enfoques realista y constructivista sobre cómo entender el ejercicio y la definición del liderazgo en defensa en la UE. El epígrafe cuarto pretende identificar los factores que caracterizan esta dimensión y que servirán como punto de referencia para construir las condiciones del análisis, detalladas en el epígrafe quinto. Finalmente se analiza el liderazgo en la construcción de la defensa europea, examinando de forma separada las condiciones necesarias y las condiciones suficientes para los países líderes y para los países que no muestran tal liderazgo.

\section{LIDERAZGO Y SEGUIDISMO EN LA PCSD}

Desde el origen de las Comunidades Europeas en la década de los años cincuenta se han intentado combinar los procesos de integración económica y defensiva. Sin embargo, la realidad estratégica de la Guerra Fría y la inviabilidad práctica de las iniciativas defensivas europeas - como la Unión Occidental (1948), la Comunidad Europea de Defensa (1954) y la congelación de la Unión Europea Occidental $(\mathrm{UEO})^{1}$ — motivaron que la seguridad europea se delegara

1 Esta surgió en 1954 tras la modificación del Tratado de Bruselas para permitir el ingreso de Alemania e Italia, descansar sobre los medios OTAN e institucionalizar el tratado que había motivado la Unión Occidental. Aunque esta organización pretendía 
en la OTAN, Washington se convirtiera en el garante de su defensa y las cuestiones estratégicas se excluyeran de la integración europea (Fatjó y Colom, 2005). Aunque coincidiendo con la distensión entre los dos bloques los seis emprendieron la Cooperación Política Europea para incrementar la visibilidad y coherencia de su acción exterior, fue necesario esperar hasta el fin de la Guerra Fría y la aprobación del Tratado de Maastricht para que Bruselas articulara mecanismos de acción exterior y seguridad. Las guerras de los Balcanes revelaron la incapacidad europea para gestionar crisis de forma autónoma, la brecha militar existente entre los aliados y la dependencia estratégica de Washington. Ello medió para que Bruselas tomara consciencia de la insostenibilidad de sus planteamientos y comprendiera que si pretendía intervenir sin recurrir a la OTAN en crisis que afectaran sus intereses debía desarrollar capacidades civiles y militares propias.

Desde entonces, el desarrollo de la PESD (1999-2007) y la PCSD (2007-) ha estado condicionado por factores políticos, estratégicos y militares. Nacida como resultado de la crisis de Kosovo como un compromiso entre las dos potencias militares europeas - la atlantista Gran Bretaña y la europeísta Francia - la PESD permitió desarrollar estructuras, capacidades, doctrinas y estrategias para la prevención de conflictos y gestión de crisis (Grevi et al., 2009). A pesar de las expectativas iniciales y los desarrollos institucionales, la PESD estuvo condicionada por la falta de una visión común sobre su naturaleza, contenido y alcance, su subordinación práctica a la OTAN, la carencia crónica de las capacidades o la escasa voluntad de emplear estas herramientas en operaciones (Witney, 2008; Toje, 2008; Fatjó y Colom, 2005).

La PCSD también ha heredado algunos de estos problemas estructurales. Codificada en el Tratado de Lisboa, esta se fundamenta en el acervo de la PESD para continuar con «[...] la definición progresiva de una política común de defensa de la Unión. Esta conducirá a una defensa común una vez que el Consejo Europeo lo haya decidido por unanimidad» (art. 42.2 TUE). Además, el Tratado codifica un catálogo de operaciones que combina las Misiones Petersberg —misiones humanitarias y de rescate, prevención de conflictos, mantenimiento de la paz y gestión de crisis, incluyendo la imposición de la paz y las operaciones conjuntas de desarme- con las contempladas en la Estrategia Europea de Seguridad de apoyo antiterrorista a terceros países y de reforma del sector de seguridad. En 2008, este catálogo de misiones se tradujo

garantizar la defensa de sus miembros frente a una agresión, la negativa a crear una estructura militar propia, la transferencia de funciones a la OTAN, el ingreso de Alemania en la Alianza o la imposibilidad de garantizar la seguridad europea sin contar con el paraguas nuclear estadounidense mediaron para que la UEO entrara en un letargo que se dilataría hasta la década de los ochenta. 
en un nivel de ambición consistente en la conducción simultánea de dos operaciones de estabilización y reconstrucción durante dos años y 10000 efectivos cada una, junto con dos operaciones de respuesta rápida empleando los Grupos de Combate y una operación de evacuación de no combatientes. Además, el Tratado introduce dos cláusulas previstas por el fallido Tratado Constitucional: una de solidaridad, por la que la UE podrá prestar asistencia a cualquier país miembro víctima de ataque terrorista o catástrofe; y otra de defensa mutua por la que se podrá responder colectivamente en caso de agresión armada contra un Estado miembro. De obligado cumplimiento para los países neutrales, esta no reemplaza los compromisos adquiridos por los aliados europeos en el marco de la OTAN.

Igualmente, el Tratado institucionaliza la Agencia Europea de Defensa (EDA) y desarrolla sus competencias para incrementar las contribuciones nacionales y mejorar las capacidades militares europeas mediante el establecimiento de objetivos comunes, el desarrollo de programas multinacionales, la armonización de requisitos, la racionalización en la obtención de material, la gestión de la I+D militar o el refuerzo de la base industrial y tecnológica de la defensa europea (arts. 42.3 y 45 TUE). Sin embargo, su valor para convertirse en el motor de la cooperación armamentística europea continúa comprometido por su limitado presupuesto, reducidas competencias y falta de voluntad política para dotarle de contenido (Fu-Chang, 2011). En consecuencia, la EDA no ha resuelto ningún problema crónico de la cooperación militar europea y no parece que los acuerdos alcanzados en el Consejo Europeo de diciembre de 2013 resuelvan esta situación (Biscop, 2014).

Finalmente, para flexibilizar la cooperación práctica en defensa, el Tratado amplía la Cooperación Reforzada (art. 20 TUE) para intensificar la colaboración entre aquellos países que lo deseen y la Cooperación Estructurada Permanente que permita a aquellos países «[...] que cumplan criterios más elevados de capacidades militares y que hayan suscrito entre sí compromisos más vinculantes al respecto» (art. 42.6 TUE). Esta puede comprender el establecimiento de acuerdos específicos para reforzar las capacidades nacionales, armonizarlas con sus socios, colaborar en proyectos militares conjuntos, integrarse en fuerzas multinacionales o participar en operaciones lideradas por la UE. Participada libremente por los países que dispongan de los medios y la voluntad necesaria para colaborar - aunque se precisa el voto unánime del Consejo y la participación de un tercio de los países- y sin ningún límite práctico más allá del cumplimiento de los compromisos, la Cooperación Estructurada Permanente es vista como un compromiso para solventar la carencia crónica de capacidades europeas, pero también para reforzar el pilar europeo de la OTAN o la base para construir un ejército europeo futuro (Grevi, Helly y Keohane, 2009; Eilstrup, 2014). 
Además, los países también pueden colaborar ad hoc o participar unilateralmente en toda la gama de operaciones de mantenimiento de la paz y gestión de crisis si poseen los medios necesarios — plasmados en la capacidad para desplegar y sostener una fuerza capaz de operar autónomamente o como parte de un componente multinacional - y obtienen el voto unánime del Consejo o valerse de la EDA para reforzar su cooperación práctica en la armonización de capacidades militares o poner en común recursos para la investigación, financiación, obtención y sostenimiento del material.

En otras palabras, el Tratado de Lisboa no solo institucionaliza la PCSD y flexibiliza la cooperación estratégica abriendo la puerta a una defensa a dos velocidades (con un núcleo integracionista interesado en profundizar en estos aspectos y con las capacidades militares necesarias para ello y otro grupo reticente o sin medios suficientes); sino que también establece los pilares necesarios para construir una defensa común si los países así lo desean. No obstante, ninguna de estas disposiciones ha sido implementada, lo que parece indicar nuevamente la falta de una visión común y la limitada voluntad política para desarrollar una defensa europea creíble y autónoma.

El inicial entusiasmo manifestado tras la firma del Tratado se convirtió en desánimo tras su entrada en vigor. La negativa irlandesa a refrendarlo y la marginación de los asuntos de defensa para facilitar el acuerdo con este país neutralista, la imposibilidad de pactar la elaboración de una nueva Estrategia Europea de Seguridad que actualizara el texto de 2003, o el nombramiento de una alta representante sin un perfil apropiado para liderar la acción exterior europea relegaron los asuntos de defensa a un segundo plano (Helwig, 2014). No obstante, sería la falta de voluntad política para implementar las provisiones del Tratado y la crisis económica que asola Europa los factores que determinaron la desaparición de los asuntos de defensa de la agenda europea y la congelación práctica de la PCSD, sumiendo a la UE en una importante crisis de identidad, considerada por algunos como la más profunda desde el fracaso de la Comunidad Europea de Defensa en 1954 (Servicio Internacional de Información de Seguridad, 2013).

Para minimizar el impacto de los recortes en defensa sobre las capacidades militares europeas y aplacar las súplicas de Washington para que Europa asuma los costes de su seguridad, Bruselas aprobó en 2010 la Iniciativa de Gante. Más conocida como Pooling and Sharing, esta pretende reforzar la cooperación en el desarrollo, obtención, mantenimiento y empleo de las capacidades militares para minimizar los efectos de la crisis sobre la defensa europea y garantizar que esta posee los medios necesarios para satisfacer sus compromisos de seguridad. Fundamentada en los principios de eficacia operativa, eficiencia económica y sostenibilidad material, esta iniciativa pretende integrar las labores de identificación de necesidades y los procesos de 
adquisición de armamento, la puesta en común de medios y estructuras o la especialización nacional en materia de capacidades militares. Aunque varios países temen que incrementará el gasto en defensa, producirá materiales que no satisfarán sus especificidades, motivará la pérdida de capacidades nacionales y erosionará su tejido industrial, la Iniciativa de Gante parece la única opción viable para conservar un mínimo de capacidades europeas en este contexto de crisis económica y persistente dividendo de la paz (Directorate-General for External Policies, 2011; Biscop, 2014).

Igualmente, para relanzar la defensa europea tras la paralización práctica de la PCSD y las cambios estratégicos que han tenido lugar desde su lanzamiento - la conclusión de la Guerra contra el Terror, el giro estadounidense hacia Asia-Pacífico o la crisis económica que ha obligado a replantear las políticas de defensa nacionales - se propuso celebrar en diciembre de 2013 un Consejo Europeo dedicado exclusivamente a la defensa. Planeado para impulsar la PCSD en tres áreas - capacidades militares, operatividad de la fuerza y cooperación en defensa- este encuentro despertó enormes expectativas que se fueron templando al observarse divergencias entre los socios europeos e incluir otros asuntos en la agenda de la reunión. Aunque finalmente se aplazaron las decisiones más importantes para futuros encuentros, se lograron varios acuerdos susceptibles de reactivar una política estancada tras la firma del Tratado de Lisboa.

Reconociendo el valor intrínseco de la defensa y su papel en la construcción europea, se acordó desarrollar la PCSD en tres dimensiones: política (avanzando en colaboración con los socios globales, transatlánticos o regionales y en complementariedad con la OTAN), capacidades (mejorando la colaboración, integrando recursos nacionales o desarrollando medios de reabastecimiento en vuelo, drones, satélites o ciberfuerzas) e industria (reestructurando el mercado y la industria, redefiniendo las responsabilidades de la EDA y estableciendo estándares armamentísticos comunes). Aunque estas decisiones no resuelven los problemas de fondo que comprometen la viabilidad de la PCSD — desde la falta de voluntad política, las culturas estratégicas opuestas, la limitada inversión en defensa, el ilusorio liderazgo de las instituciones europeas, las carencias industriales o la reducida competitividad del mercado de defensa europeo- sí pueden reducir la parálisis que está afectando la defensa europea (Helwig, 2014).

\section{REALISMO Y CONSTRUCTIVISMO: DIFERENTES FORMAS DE ENTENDER EL LIDERAZGO}

La configuración de la PESC, la PESD y la actual PCSD ha recibido una gran atención por parte de la comunidad académica europea. Aunque su 
desarrollo se ha estudiado desde múltiples enfoques, destacan los (neo)realistas y los constructivistas (Breuer, 2010; Pohl, 2013). Los primeros relativizan el valor de la PCSD al entender que ningún Estado resolverá su dilema de seguridad delegando la defensa nacional en manos de una organización supranacional como la $\mathrm{UE}^{2}$. En consecuencia, no creen que pueda producirse ninguna convergencia en materia defensiva ni tampoco la puesta en común de los medios militares nacionales. Además, al existir más de una solución al dilema de seguridad específico de cada país (la suficiencia nacional, los convenios bilaterales, la UE o la OTAN), distintas percepciones de la amenaza y múltiples culturas estratégicas (neutralistas, europeístas o atlantistas), estos entienden que los gobiernos europeos difícilmente cooperarán en defensa, y si lo hacen será de forma bilateral o multilateral pero sin delegar la defensa a Bruselas para no comprometer su autonomía estratégica (Rynning, 2011; Dyson, 2013; Eilstrup, 2014).

Sin embargo, no descartan la colaboración militar (Glaser, 1995), puesto que todos los europeos —especialmente aquellos que forman parte de la OTAN - se hallan en un dilema similar, ya que deben mantener capacidades suficientes para satisfacer sus compromisos de seguridad, minimizar el impacto de los recortes en defensa y conservar la interoperabilidad con Estados Unidos. En consecuencia, para resolver este problema la opción más racional y asequible es la cooperación, aunque esta tenderá a realizarse en el marco aliado debido a la naturaleza de esta organización, su orientación hacia la defensa colectiva de sus miembros, el liderazgo estadounidense y la disuasión que este proporciona con su arsenal nuclear y la presencia de fuerzas del país en suelo europeo (Posen, 2006; Rynning, 2011; Dyson, 2013) .

No obstante, el paradigma dominante en el análisis de la PCSD es el constructivismo, que asume que la construcción europea genera un proceso de

2 Un dilema de seguridad surge cuando las acciones realizadas por un Estado para reforzar su propia seguridad provocan un sentimiento de inseguridad entre sus vecinos. Al percibir estas acciones como una amenaza a su seguridad porque alteran el equilibrio militar existente, estos Estados incrementarán sus capacidades militares como respuesta, provocando así una escalada de tensiones y una carrera de armamentos que puede desembocar en un conflicto (Jervis, 1978; Herz, 1951).

3 Paradójicamente, el arranque de la PESD fue visto con recelo por Washington porque temía que limitaría la hegemonía americana y comprometería la centralidad de la Alianza, argumentando que cualquier avance en esta materia se basara en la no discriminación de los miembros no europeos de la OTAN, la no división de la seguridad transatlántica y la no duplicación de medios ni estructuras militares. Actualmente la situación es diametralmente opuesta y Washington insta repetidamente a que los europeos incrementen sus propias capacidades de defensa. 
socialización que está motivando la consolidación de una cultura estratégica típicamente europea y la convergencia de las políticas de defensa nacionales hacia una defensa común que reducirá las tendencias anárquicas del sistema internacional y cubrirá las necesidades de seguridad europeas (Meyer, 2005). Así, la construcción del liderazgo nacional en el desarrollo de la PCSD estaría más vinculada con una voluntad política forjada por un proceso de socialización que en la posesión de capacidades militares nacionales ${ }^{4}$, ya que estas podrán generarse conjuntamente siguiendo los objetivos de fuerzas (Force Objectives) y capacidades (Headline Goals) delineados por Bruselas desde 1999.

Asumiendo estos elementos, seguidamente se observará la configuración del liderazgo en la defensa europea. Aunque la literatura se interesa principalmente por los factores normativos o los desarrollos institucionales de la PCSD, también pueden hallarse otros trabajos que observan indirectamente el liderazgo militar en la UE. Ejemplos de ello son los que analizan los mecanismos de cooperación armamentística como herramienta para avanzar en la construcción europea (Fu-Chang, 2011); los que estudian las razones del atlantismo o europeísmo de los países observando su cultura estratégica o decisiones políticas (Cornish y Edwards, 2001; Toje, 2008; Pohl, 2013); o los que emplean enfoques constructivistas para explicar la bruselización de la PCSD y cómo las interacciones que allí se realizan contribuyen a la construcción de una defensa común (Breuer, 2011) y la definición de una concepción estratégica europea (Rogers, 2009). Es decir, estos estudios analizan los motivos que inducen a la colaboración europea en defensa, las razones que explican la predilección nacional por la UE o la OTAN o el liderazgo y seguidismo (bandwagoning) en la seguridad europea, priorizando los aspectos estratégicos pero obviando los factores que explican que unos países sean proclives a cooperar, liderar o ser liderados. Precisamente, este artículo pretende analizar estos aspectos y descubrir por qué unos países actúan como líderes y otros prefieren - bien sea por su vocación atlantista, pacifista o por su carencia de capacidades - adoptar una postura pasiva en el desarrollo de la PCSD.

Así, el trabajo se basará en las siguientes hipótesis configuracionales: partiendo de la idea de que el liderazgo europeo en defensa requiere tanto la posesión de capacidades militares como la voluntad política para contribuir a su desarrollo, la primera hipótesis (H1) plantea que la posesión de una estrategia nacional de seguridad bien articulada constituye una condición necesaria para que un Estado pueda asumir rasgos de líder. La segunda hipótesis (H2) asume que si bien la voluntad política (de tener una estrategia ambiciosa) es una

4 Una capacidad militar se compone de doctrina, organización, adiestramiento, material, liderazgo y educación, personal e infraestructuras. 
condición necesaria para que un país pueda liderar el desarrollo de la PCSD, si este carece de capacidades que la sustenten nunca podrá erigirse como líder en esta materia. De esta forma, la voluntad política es una condición necesaria pero no suficiente para la ocurrencia del resultado.

\section{LOS FACTORES QUE IMPULSAN EL DESARROLLO DE LA PCSD}

Tras haber expuesto el desarrollo de la PCSD, ahora es momento de preguntarse cuáles son los factores que impulsan esta política, cuáles son sus condicionantes o qué países pueden liderar el proceso. Así, puede argumentarse que cualquier avance en la defensa europea requiere valores para desarrollarla, voluntad política para impulsarla, capacidades militares para apoyarla y una cultura estratégica específica para priorizarla frente a otras opciones como la Alianza Atlántica, la cooperación multilateral ad hoc o la autarquía.

Formalmente, la PCSD es de naturaleza intergubernamental, por lo que cualquier desarrollo requiere el voto unánime de los miembros. No obstante, ante las dificultades para avanzar en este proceso, el Tratado de Lisboa adopta un enfoque más flexible que permite a los países que así lo deseen incrementar su colaboración mediante la firma de Cooperaciones Reforzadas en tres áreas - capacidades, operaciones e industria - y así acelerar su integración en materia defensiva. Sin embargo, mientras las Cooperaciones Reforzadas están abiertas a los países que lo deseen (voluntad política); si pretenden participar en la Cooperación Estructurada Permanente deben poseer un mínimo de capacidades militares (codificadas por el cuarto protocolo del Tratado de Lisboa y basadas en la participación en un Grupo de Combate y en un proyecto militar multinacional) y en la determinación (voluntad, capacidad y cultura estratégica) de utilizarlas en operaciones en el exterior. Aunque no han sido utilizadas, estas disposiciones pueden contribuir a resolver la carencia crónica de medios militares europeos y avanzar en el desarrollo de la PCSD.

En consecuencia, para entender las contribuciones nacionales a la defensa europea se deben observar tanto los factores objetivos como los elementos subjetivos. Los primeros muestran la naturaleza, entidad y volumen de la participación nacional en términos de fuerzas, medios o capacidades y son fundamentales tanto para elaborar los catálogos de fuerzas y los objetivos de capacidades que vienen elaborándose desde el Helsinki Headline Goal como para determinar la capacidad de un país para participar en Cooperaciones Reforzadas. Por su parte, los segundos condicionan la voluntad nacional por contribuir a la defensa europea, la propensión en adoptar una postura pasiva o activa en su desarrollo, el interés por participar en programas conjuntos o la determinación por ahondar en la colaboración mediante la Cooperación Estructurada Permanente. 
Además, mientras los factores objetivos son fácilmente cuantificables, las voluntades políticas no lo son. Hasta la fecha, la noción de voluntad politica ha sido determinante para explicar el relativo fracaso de la defensa europea (Whitney, 2008). Aunque el Tratado de Lisboa flexibiliza su desarrollo posibilitando tanto la conducción de operaciones europeas empleando el principio de nación líder (donde un país se responsabiliza de la operación y proporciona los medios necesarios) o introduciendo la Cooperación Estructurada Permanente para posibilitar una defensa a dos velocidades, la situación actual muestra cómo la integración en esta materia es menos satisfactoria de lo deseado. La escasa voluntad política y la crisis económica que azota el continente no solo han impedido implementar las disposiciones del Tratado y paralizado cualquier desarrollo en esta materia, sino que también están motivando las cooperaciones ad hoc para limitar el impacto de la crisis sobre las defensas nacionales 5 . Precisamente, para reconducir esta situación, tanto la OTAN con su Smart Defence como la UE con su Pooling and Sharing han implementado iniciativas de colaboración en materia de medios, fuerzas y capacidades.

No obstante, aunque la cooperación armamentística es considerada como una efectiva estrategia para crear un mercado europeo de defensa, estandarizar los medios militares europeos e impulsar la PCSD, las especificidades de este sector entorpecen la colaboración. A diferencia de otros sectores sujetos a las normas comunitarias y del reglamento de 2011 sobre los mercados públicos de defensa (que pretende incrementar la competencia industrial, reducir duplicidades y abaratar los costes del armamento), los países continúan adoptando políticas proteccionistas de su industria nacional aplicando excepciones al mercado común por motivos de seguridad nacional en materia de producción, adquisición y venta de armamento (art. 346 del Tratado de Funcionamiento de la UE) (Trybus, 2014).

En consecuencia, en este contexto marcado por factores objetivos, consideraciones estratégicas e intereses políticos, los países deben decidir acerca de sus contribuciones, agendas y roles: deben elegir su marco de seguridad

5 No obstante, también existen numerosos acuerdos de colaboración realizados al margen de Bruselas como el Tratado de Cooperación en Defensa y Seguridad entre Francia y Gran Bretaña para compartir medios aéreos y navales, crear una fuerza expedicionaria conjunta, colaborar en el campo del armamento nuclear y concurrir en proyectos de investigación militar, la creación de una unidad anfibia conjunta entre el Reino Unido y los Países Bajos, la constitución de una universidad de la defensa entre los países bálticos, la cooperación en adiestramiento y mantenimiento de sistemas entre el BENELUX, el Batallón Nórdico entre Suecia, Noruega, Finlandia y Dinamarca o el Mando de Transporte Aéreo Europeo entre Bélgica, Francia, Alemania, Luxemburgo, España y Países Bajos. 
(OTAN, UE o neutralidad), determinar su compromiso (alto, medio o bajo) y resolver sus carencias nacionales manteniendo la autonomía, participando en proyectos bilaterales o multilaterales ad hoc o colaborando en el marco aliado o europeo. Por lo tanto, los países deben decidir si prefieren apoyar el desarrollo de la PCSD tomando una posición secundaria, optar por las Cooperaciones Reforzadas para liderar la integración militar europea, confiar en la OTAN - y por lo tanto en el paraguas estadounidensey asumiendo una posición pasiva o adoptar una posición neutralista o aislacionista.

Además de la voluntad política, la cultura estratégica también puede explicar el compromiso nacional con la defensa europea. Entendida como el conjunto de factores objetivos (geografía, demografía, economía o historia) y subjetivos (ideas, valores, creencias o tradiciones militares derivadas tanto de la cultura como de las experiencias pasadas) que explican la percepción que tienen los Estados acerca del empleo de la fuerza armada o su predilección por un estilo militar concreto, la cultura estratégica condiciona la configuración de las políticas de defensa nacionales (Longhurst, 2000: 301-303). Con independencia de las tesis que asumen que Europa está desarrollando una cultura estratégica común (Meyer, 2005), esta idea también puede explicar la propensión de algunos países para priorizar el desarrollo de la PCSD en detrimento de otras iniciativas (Biehl et al., 2013).

De hecho, la voluntad política y la cultura estratégica pueden explicar el tradicional dualismo entre las dos potencias militares europeas, el Reino Unido y Francia. Mientras el primero es un ferviente atlantista y tibio defensor - cuando no opositor - de la defensa europea por su temor a que esta erosione el vínculo trasatlántico y comprometa su «relación especial» con Washington, Francia ha sido la principal promotora y máxima valedora de la PCSD para reforzar su posición europea mientras erosiona —al menos hasta su retorno a la estructura militar integrada en 2009- el liderazgo aliado y estadounidense. Enfoques similares también pueden hallarse entre una vieja Europa más proclive a participar en la PCSD y una nueva Europa que tiende a confiar en la OTAN - y más específicamente en Washington - para garantizar su seguridad frente a una amenaza latente de Moscú que, tras las crisis de Crimea y Ucrania, parece cada vez más patente (Larsen, 2014).

Finalmente, la pertenencia a organizaciones internacionales también puede contribuir a explicar la participación nacional en la PCSD. De hecho, la integración de un país en el sistema de seguridad colectiva dificulta el recurso a la guerra y hace que sus líderes políticos, opinión pública y fuerzas armadas sean más proclives a participar junto con otros países en operaciones de paz, mejorando la interoperabilidad con otros ejércitos y socializando a las élites políticas y militares. 


\section{METODOLOGÍA, CONSTRUCCIÓN DEL OUTCOME Y SELECCIÓN DE CONDICIONES}

\section{LA TÉCNICA FSQCA}

La técnica fuzzy set QCA fue desarrollada por Charles Ragin (2000, 2008) para posibilitar el uso de la lógica borrosa en el procedimiento analítico desarrollado para la técnica csQCA que, presentada en su obra The Comparative Method (1987), permitía analizar comparativamente estudios con $\mathrm{N}$-intermedia. El fsQCA permite trabajar con matrices de datos cuya información difícilmente responde a una lógica dicotómica o multicotómica, proporcionando un procedimiento para calibrar datos numéricos e índices que capturen cierta gradación, incluso ordenación, entre los casos. A diferencia del empleo que se da a la lógica borrosa en matemáticas para expresar la borrosidad lingüística de fenómenos (Zadeh, 1965), la propuesta de Ragin tiene un propósito comparativo dentro de los métodos de conjuntos teóricos. En consecuencia, el fsQCA se compone de un procedimiento para calibrar matrices de datos de naturaleza numérica para hacerlas coincidir, aplicando grados de pertenencia a conjuntos, con variaciones interválicas entre $[0,1]$ detallando la localización del punto de máxima indefinición, conocido como cross-over point $[0,5]$. El outcome debe expresarse en valores fuzzy, mientras que, en caso de estar justificado, se permite que alguna condición sea presentada de forma dicotómica.

Asimismo, la propuesta de Ragin asemeja el procedimiento analítico de fsQCA con el establecido para csQCA (crisp-set Quantitative Comparative Analysis) al recurrir formalmente —al menos en lo referente al programarioa tablas de verdad, la minimización de condiciones, el uso de implicantes primarios, el análisis de condiciones suficientes y el análisis de condiciones necesarias. También se ofrecen similares mecanismos de evaluación del análisis atendiendo a medidas de consistencia y cobertura de los modelos. Como novedad, se ofrecen $X Y$ Plots para inspeccionar criterios de necesidad y suficiencia de las condiciones. Aunque en apariencia e interpretación el fsQCA funcione a grandes rasgos igual que csQCA, la lógica detrás de fsQCA se fundamenta en grados de pertenencia de los casos a conjuntos difusos (a diferencia de las pertenencias absolutas que hallamos en csQCA), expresados como «vectores espaciales multidimensionales» (a diferencia de las filas dentro de las tablas de verdad).

Así, el fsQCA permite analizar presencia y ausencia del outcome siguiendo el algoritmo Quine-McCluskey, incorporar condiciones que han sido calibradas a partir de matrices de datos interválicas, realizar operaciones de negación, disyunción y conjunción, analizar condiciones necesarias siguiendo las 
directrices de consistencia y cobertura, así como examinar la equifinalidad derivada del análisis de condiciones suficientes, habitualmente presentadas de forma combinatoria. Durante la especificación de la consistencia de las configuraciones en la tabla de verdad, también encontramos — como en csQCAel requisito de identificar estados de veracidad y falsedad de los casos, contrafácticos y logical remainders que evidencian la diversidad limitada de los estudios comparados y que sirven para producir, una vez indicadas las expectativas direccionales, soluciones intermedias —además de complejas y parsimoniosas - en el análisis de las condiciones suficientes.

La justificación de la selección de fsQCA responde, por un lado, a que este artículo analiza veinticinco casos de los veintiocho que conforman la UE salvo Croacia, Dinamarca y Chipre. Su exclusión responde a que Croacia ingresó en la UE en julio de 2013 y está comenzando ahora a participar en las iniciativas en defensa, por lo que sería injusto incluirla en este análisis. Además, las últimas tablas nacionales recopiladas por la EDA proceden de 2012, por lo que varios datos en materia presupuestaria no están todavía normalizados al estándar europeo. Por otro lado, el descarte de Dinamarca responde a su cláusula de exclusión (opt-out), por la que no participa en ninguna iniciativa vinculada con la PCSD, mientras que el descarte de Chipre se debe a que, en la práctica, no participa en ningún proyecto europeo, no mantiene fuerzas en el exterior (entre 2009 y 2012 no ha superado los cuatro efectivos), no contribuye con unidades militares en el Grupo de Combate del que forma parte (el BG-HELBROC liderado por Grecia) y sus sistemas armamentísticos son de procedencia rusa y no armonizados con el estándar OTAN, y por lo tanto no interoperables con los europeos. Por otro lado, se recurre a fsQCA por la naturaleza numérica de condiciones relevantes en el análisis de las que una dicotomización sería contraproducente e injustificada. En el subepígrafe V.3 se detallan las reglas y el método de calibración empleados para cada condición.

\section{CONSTRUCCIÓN Y CALIBRACIÓN DEL OUTCOME (PAÍSES LÍDERES EN DEFENSA)}

La revisión de la literatura muestra cómo la conceptualización del liderazgo en defensa se plantea a menudo de forma parcial, identificando la voluntad política de los países, sus volúmenes de fuerza y catálogos de capacidades militares o sus culturas estratégicas. Esto conduce a múltiples formas de ejercer el liderazgo y, por lo tanto, a múltiples ordenaciones de los países. Consideramos que toda clasificación parcial carece de utilidad para una definición compleja del liderazgo, por lo que optamos por construir un índice lo más abarcador posible a partir de la inclusión de indicadores relevantes considerados por autores de referencia. 
Como resultado, creamos un índice cualitativo de liderazgo a partir de ocho indicadores englobados en tres subíndices: a) capacidad militar (integrado por la inversión en armamento o el volumen de sus fuerzas armadas); b) capacidad industrial (compuesto por la capacidad exportadora de armamento, la participación en proyectos militares multinacionales y el gasto en $\mathrm{I}+\mathrm{D}$ militar) y c) contribución a la PCSD (definida por el liderazgo nacional de un Grupo de Combate y la priorización de la PCSD como proyecto de defensa).

La regla para valorar el liderazgo $(Y=1)$ para los indicadores es la siguiente:

- Capacidad para invertir sustancialmente en equipamiento militar: se considera que el país es líder cuando las partidas de adquisición de armamento superan los mil millones de euros anuales para garantizar la obtención de plataformas aéreas (aviones de combate) y navales (grandes buques de superficie o submarinos) tecnológicamente avanzadas y económicamente muy costosas (año de referencia: 2012, fuente: EDA). No se emplea el presupuesto relativo porque la capacidad de compra de equipamiento - y con ello el volumen de las capacidades militares - está determinada por el capital disponible, y por lo tanto debe observarse en términos absolutos.

- Potencial militar efectivo de las fuerzas armadas: se considera que el país es líder cuando posee un ejército moderno (cuyos principales medios materiales han entrado en servicio tras la Guerra Fría), con un amplio catálogo de capacidades adecuadas al entorno operativo actual (unos ejércitos no orientados exclusivamente hacia la defensa territorial sino también hacia la proyección militar más allá de su entorno estratégico inmediato) y con medios de despliegue y sostenimiento autónomo de la fuerza (con aviones de transporte interteatro o estratégico y buques de proyección).

- Capacidad exportadora de armamento: se considera que el país es líder cuando es uno de los veinte principales exportadores de armamento pesado y tecnológicamente avanzado del globo (período de referencia: 2009-2013, fuente: sipri.org).

- Gasto en I+D militar: se considera que el país es líder cuando esta partida supera los 50 millones de euros o el $0,5 \%$ del presupuesto anual de defensa, tal y como sugirió la OTAN en la Cumbre de Gales (2014) en el marco de la Smart Defence cuando propuso incrementar el gasto militar nacional hasta el $2 \%$ del Producto Interior Bruto (año de referencia: 2012, fuente: EDA).

- Participación en proyectos colaborativos europeos: se considera que un país es líder cuando participa en uno o más proyectos armamentísticos multinacionales - como pueden ser los aviones de combate 
EF-2000 y transporte A-400M o los helicópteros de combate EC-665 y multipropósito NH-90, como ejemplos más representativos- bajo el amparo de la EDA. En este sentido, es importante recordar que la participación en uno o más proyectos de este tipo constituye - junto con el liderazgo de uno o más Grupos de Combate- la condición básica para participar en la Cooperación Estructurada Permanente.

- Liderazgo de un Grupo de Combate: se considera líder cuando es el país marco de una o más de estas fuerzas de maniobra porque de ello dependerá su hipotética participación en la Cooperación Estructurada Permanente.

- Liderazgo en el mantenimiento de la PCSD: se considera que el país es líder cuando colabora activamente — proponiendo medidas políticas, cooperando en la definición de los catálogos civiles y militares o poniendo a disposición de Bruselas los medios materiales necesarios para operaciones - en su desarrollo institucional.

La confección de la condición liderazgo en defensa que opera como fenómeno a explicar en este trabajo queda resuelta en la tabla 1, que permite visualizar los valores nacionales e indicador, así como el sumatorio final de cada país que oscila entre 0 y 7 , atendiendo a que el valor mínimo y máximo para cada indicador se establece de forma dicotómica [0] o [1]. Se ha empleado el método de calibración directa estableciendo el punto de total pertenencia en el valor 6 (que indica tanto la posesión de capacidades militares como la voluntad política para contribuir al desarrollo de la PCSD); el punto de mayor indefinición en el valor 4 (porque la carencia de tres indicadores evita que un país pueda participar en la práctica en la Cooperación Estructurada Permanente a pesar de disponer de un ejército capaz) y la total exclusión en el valor 2 (porque su ejército no solo carece de capacidades militares avanzadas y no puede colaborar en el desarrollo operativo de la PCSD, sino que esta situación difícilmente se resolverá en un futuro próximo al carecer de la capacidad inversora suficiente).

\section{SELECCIÓN Y CALIBRACIÓN DE LAS CONDICIONES}

Tras haber construido la condición que funcionará como outcome (LIDERAZGO) en nuestro análisis, justificaremos ahora la selección del resto de condiciones. La lógica empleada para seleccionar seis condiciones ${ }^{6}$ responde a

6 Con 25 casos y seis condiciones, el benchmark para la evaluación de la especificación del modelo se establece al 10\%, que, según las aportaciones de Marx et al. (2013), entra dentro de los supuestos metodológicos aceptados. Además, Marx y Dusa (2011) 
Tabla 1. Construcción de la condición LIDERAZGO

\begin{tabular}{|c|c|c|c|c|c|c|c|c|}
\hline \multirow{2}{*}{ País } & \multicolumn{2}{|c|}{ Capacidad militar } & \multicolumn{3}{|c|}{ Capacidad industrial } & \multicolumn{2}{|c|}{ Contribución a PCSD } & \multirow{2}{*}{ LIDERAZGO } \\
\hline & Inversión & FAS & Exportación & Proyectos & $\mathrm{I}+\mathrm{D}$ & Liderazgo & Battlegroup & \\
\hline Austria & 0 & 0 & № $(0)$ & 0 & 0 & № $(0)$ & No $(0)$ & 0 \\
\hline Bélgica & 0 & 0 & No $(0)$ & 1 & 0 & No $(0)$ & No $(0)$ & 1 \\
\hline Bulgaria & 0 & 0 & No $(0)$ & 0 & 0 & No $(0)$ & No $(0)$ & 0 \\
\hline Rep. Checa & 0 & 0 & No $(0)$ & 0 & 0 & No $(0)$ & SÍ (1) & 1 \\
\hline Estonia & 0 & 0 & No $(0)$ & 0 & 0 & No $(0)$ & No $(0)$ & 0 \\
\hline Finlandia & 0 & 0 & No $(0)$ & 0 & 0 & SÍ (1) & No $(0)$ & 1 \\
\hline Francia & 1 & 1 & SÍ (1) & 1 & 1 & SÍ (1) & SÍ (1) & 7 \\
\hline Alemania & 1 & 1 & SÍ (1) & 1 & 1 & SÍ (1) & SÍ (1) & 7 \\
\hline Grecia & 0 & 0 & No $(0)$ & 0 & 0 & SÍ (1) & SÍ (1) & 2 \\
\hline Hungría & 0 & 0 & No $(0)$ & 0 & 0 & No $(0)$ & No $(0)$ & 0 \\
\hline Irlanda & 0 & 0 & № $(0)$ & 0 & 0 & No $(0)$ & No $(0)$ & 0 \\
\hline Italia & 1 & 1 & SÍ (1) & 1 & 1 & SÍ (1) & SÍ (1) & 7 \\
\hline Letonia & 0 & 0 & № $(0)$ & 0 & 0 & № $(0)$ & No $(0)$ & 0 \\
\hline Lituania & 0 & 0 & No $(0)$ & 0 & 0 & No $(0)$ & No $(0)$ & 0 \\
\hline Luxemburgo & 0 & 0 & No $(0)$ & 1 & 0 & No $(0)$ & No $(0)$ & 1 \\
\hline Malta & 0 & 0 & No $(0)$ & 0 & 0 & No $(0)$ & No $(0)$ & 0 \\
\hline Holanda & 1 & 0 & SÍ (1) & 1 & 1 & No $(0)$ & No $(0)$ & 4 \\
\hline Polonia & 1 & 1 & No $(0)$ & 0 & 1 & No $(0)$ & SÍ (1) & 4 \\
\hline Portugal & 0 & 0 & № $(0)$ & 0 & 0 & No $(0)$ & SÍ (1) & 1 \\
\hline Rumanía & 0 & 0 & No $(0)$ & 0 & 0 & No $(0)$ & No $(0)$ & 0 \\
\hline Eslovaquia & 0 & 0 & No $(0)$ & 0 & 0 & No $(0)$ & No $(0)$ & 0 \\
\hline Eslovenia & 0 & 0 & № $(0)$ & 0 & 0 & № $(0)$ & № $(0)$ & 0 \\
\hline España & 1 & 1 & SÍ (1) & 1 & 1 & SÍ (1) & SÍ (1) & 7 \\
\hline Suecia & 1 & 0 & SÍ (1) & 1 & 1 & SÍ (1) & SÍ (1) & 6 \\
\hline Reino Unido & 1 & 1 & SÍ (1) & 1 & 1 & SÍ (1) & SÍ (1) & 7 \\
\hline
\end{tabular}

Fuente: Elaboración propia. 
la voluntad de analizar la relevancia de tres factores clave según el (neo)realismo y tres factores importantes para el constructivismo. Así, como ya se discutió anteriormente, la aproximación realista a la PCSD difícilmente simpatiza con la idea de una defensa común en la que la convergencia de intereses y la cooperación militar sean los factores determinantes. Al contrario, estos reivindican el significado del poder político en tanto que capacidad de intervención militar (PRESUPUESTO, EJERCITO), especialmente de los países de Europa Occidental cuya experiencia histórica y cultura estratégica dentro de la UE es mayor que los países de Europa Oriental (ESTE). Por oposición, el constructivismo reivindica el espacio de unos valores estratégicos compartidos (ESTRATEGIA) que permiten la cooperación entre los países tanto en la creación de redes (ALIANZAS) como de capacidades militares (PROYECCION).

De forma breve, la construcción de la matriz de datos y su posterior calibración se han planteado de la siguiente forma para cada una de las condiciones (véase la tabla 2, que ofrece un resumen detallado de la matriz de datos y la calibración de las condiciones).

realizaron una de las innovaciones más relevantes para la buena configuración de los modelos en QCA. Plantearon la posibilidad de crear modelos plagados de contradicciones y escasamente consistentes, aspecto directamente relacionado con el número de casos y el número de condiciones. Hasta el momento existían algunas buenas prácticas, como mantener un número relativamente pequeño de condiciones a pesar de no existir un «indicador» metodológico que estableciera los límites. Marx y Dusa establecieron dichos límites en dos sentidos. En relación con el problema de las "contradicciones», apuntaron lo siguiente: «Researchers are advised to specify their model (the ratio of conditions to cases) in such a way that on the basis of random data contradictions should be omnipresent or at least $90 \%$ of the random samples should generate contradictions» (2011: 114). Los modelos con 25 casos y 6 condiciones (excluyendo el resultado) adquieren un valor de 0,91 en la «medida de contradicciones», siendo perfectamente sólido en términos metodológicos. Por otra parte, los autores añadieron también la "consistencia» del modelo, expresada en los siguientes términos (2011: 116): "csQCA seems able, on the basis of our chosen measure, to generate highly consistent results on random data. If one takes the 0.75 score (supra) as a point of departure the models which are specified according to the dark area would considered to be highly consistent, even on random data». En consecuencia, un modelo con 25 casos y 6 condiciones explicativas cumple con el requisito de consistencia (con un valor de 0,83 ). 


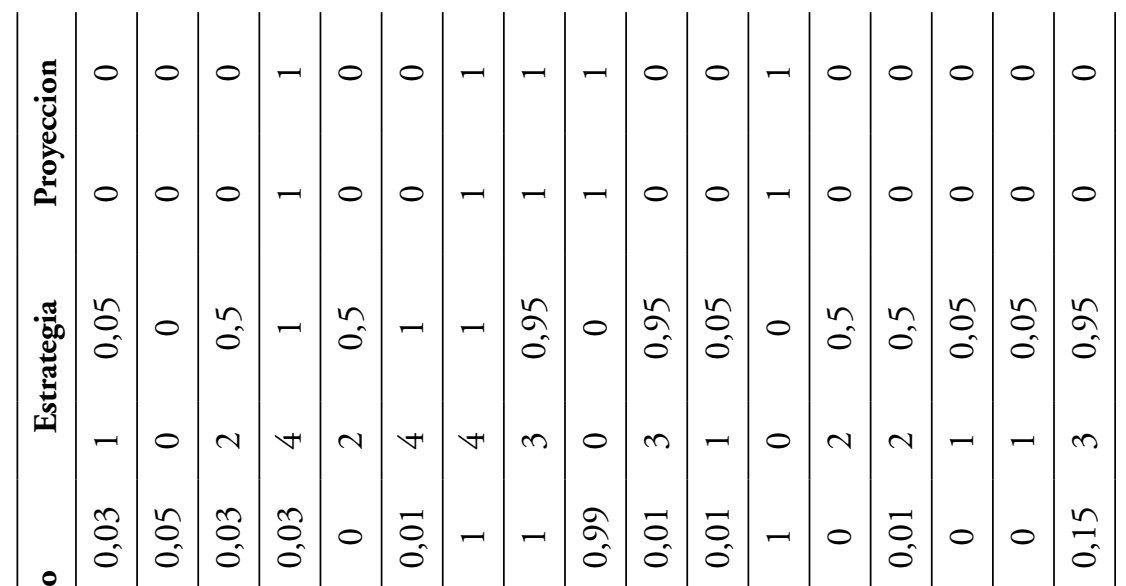
.

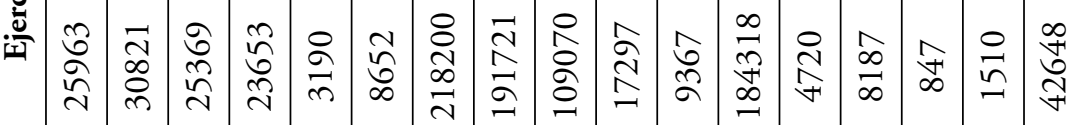

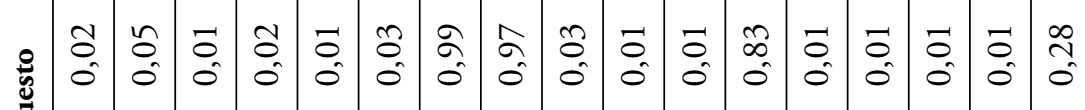

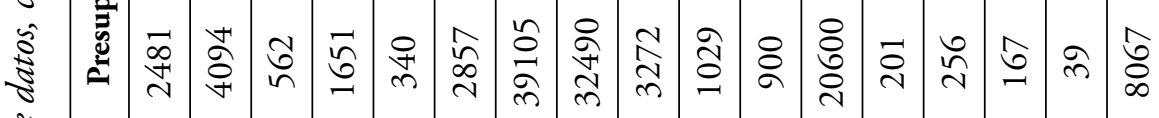

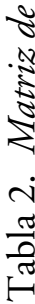

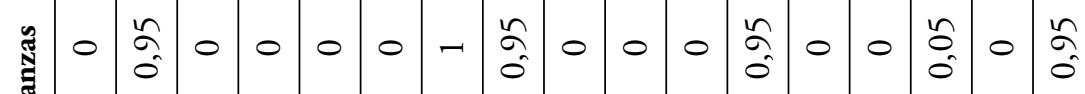

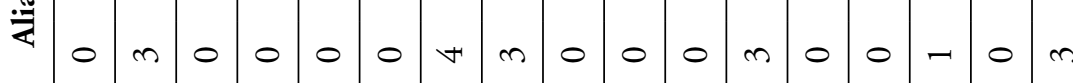

$$
\begin{aligned}
& \begin{array}{lllllllllllllllllll}
5 & 0 & 0 & - & - & - & 0 & 0 & 0 & 0 & - & 0 & 0 & - & - & 0 & 0 & 0 \\
0 & 0 & - & - & - & 0 & 0 & 0 & 0 & - & 0 & 0 & - & - & 0 & 0 & 0
\end{array}
\end{aligned}
$$

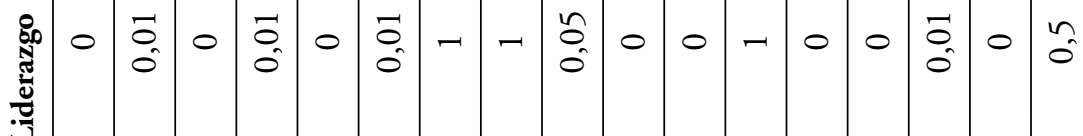

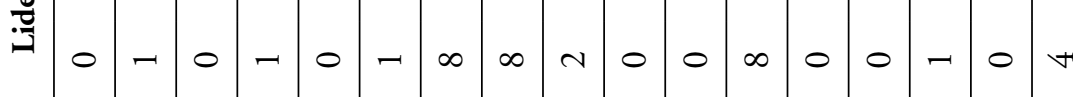

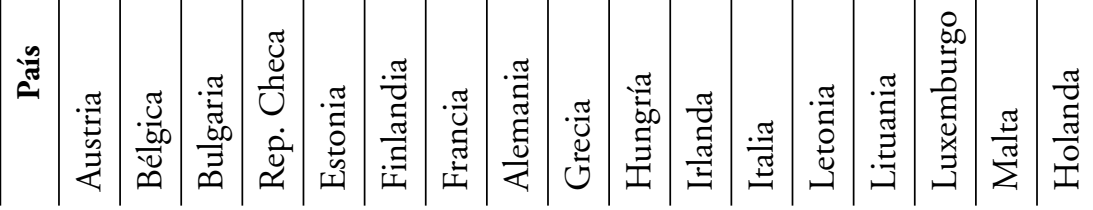




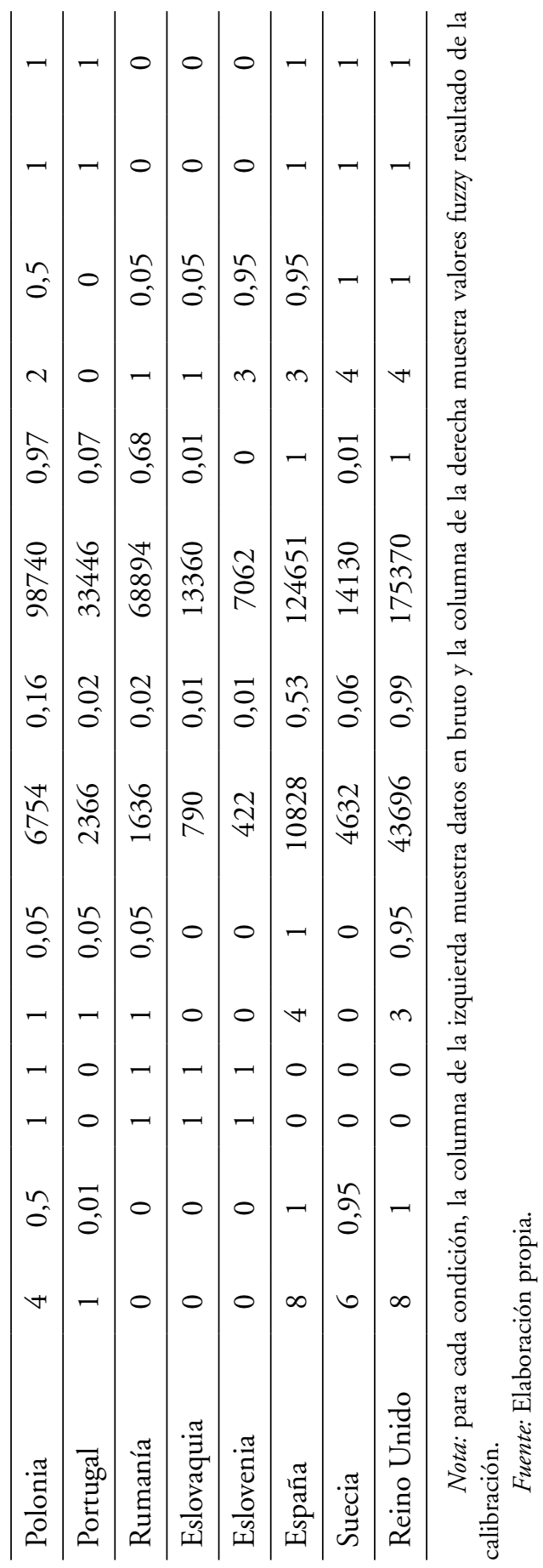


- ESTE: los países han sido clasificados de forma dicotómica según su pertenencia a la Europa del Este (estos estados formaban parte del Pacto de Varsovia durante la Guerra Fría, se vieron obligados a transformar su estructura de fuerzas, catálogo de capacidades y doctrinas militares tras su integración en la OTAN y la UE, y han sido los últimos en participar en el desarrollo de la PCSD) por la asignación de valor [1], responde a total pertenencia al conjunto de países del Este, mientras que el valor [0] representa la exclusión del conjunto.

- ALIANZAS: la matriz considera el número total de organizaciones de cooperación en materia de seguridad y defensa europeas de las que cada país forma parte. Se tienen en cuenta las cuatro principales estructuras europeas al margen de la EDA y la PCSD por ser organismos de participación mayoritaria, a saber, el Mando de Transporte Aéreo Europeo (EATC), la Organización Conjunta para la Cooperación de Armamentos (OCCAR), la Fuerza de Gendarmería Europea (EUROGENDFOR) y el Grupo Aéreo Europeo (EAG). En consecuencia, no se tienen en cuenta las unidades combinadas al servicio de la UE, como la Fuerza Marítima Europea (EUROMARFOR) o el Cuerpo de Ejército Europeo (EUROCORPS). Con valores oscilando entre [0] y [4], la calibración -mediante método de calibración directa - fija la total pertenencia en el valor [3] porque varios países no contribuyen a EUROGENDFOR al carecer de unidades paramilitares para ser utilizadas en labores de seguridad pero participan en las iniciativas de defensa; el punto de máxima indefinición en el valor [2] porque indica que no colaboran en alguno de los programas de obtención o puesta en común de capacidades; y la total exclusión en el valor [1] porque revela la falta de voluntad o la incapacidad militar del país para participar en estas iniciativas.

- PRESUPUESTO: a partir de datos correspondientes al presupuesto en defensa para 2012, los anclajes teóricos se establecen en 30000 millones de euros para la total pertenencia al conjunto al tratarse de un montante que garantiza fondos suficientes para disponer de una estructura de fuerzas, un catálogo de capacidades militares y unos proyectos de modernización de material suficientes como para combatir en toda la gama de las operaciones; 10000 millones de euros para el cross-over point porque con este volumen de gasto es inviable mantener un catálogo de capacidades que permita satisfacer todo el conjunto de contingencias, y 4000 millones de euros para la total exclusión, ya que con este gasto es completamente inviable proyectar la fuerza al exterior. Cabe apuntar que la matriz de datos refleja una variación considerable entre el país con el mayor (Reino Unido 
con 43696 millones de euros) y el menor presupuesto (Malta con 39 millones de euros).

- EJERCITO: con 2012 como referencia, la matriz de datos incluye el número total de personal militar nacional, que oscila entre los 218200 efectivos de Francia y los 847 de Luxemburgo. Siguiendo el método directo de calibración, los anclajes teóricos se establecen en 95000 efectivos - que permite satisfacer las necesidades de defensa nacional, contribuir a la defensa colectiva, asignar fuerzas a los Battlegroups europeos, la Standing High Readiness Brigade de las Naciones Unidas y la NATO Response Force aliada y sostener varias rotaciones en operaciones en el exterior - para total pertenencia; 60000 efectivos para el cross-over point porque con este volumen de fuerzas ya no es posible mantener las rotaciones para satisfacer todos los cometidos y 30000 para la exclusión porque es inviable desplegar y sostener unidades de combate en el exterior.

- ESTRATEGIA: se toma como referencia el trabajo de De France y Witney en el que se revisan cualitativamente, mediante un análisis documental de las estrategias de seguridad, los esfuerzos nacionales en contribuir coherente y operativamente a la PCSD. Estos proponen una clasificación cualitativa de los países de menos a más estratégicos que incluye a países polizones, abstencionistas, localistas, globalistas y estrategas. Partimos de esta gradación cualitativa (ahora códigos cualitativos) para crear un índice agregado —una variable interválica- de esfuerzos estratégicos con un rango de $(0,4)$, siendo 0 el valor para los polizones y 4 el de los estrategas. La calibración establece la total pertenencia en el valor [3], incluyendo a los globalistas y estrategas como países con estrategias ambiciosas; el punto de indefinición en el valor [2], países localistas que cuentan con estrategias avanzadas pero delimitadas a un radio geográfico limitado, y la exclusión en el valor [0], donde los países abstencionistas y polizones no presentan, cualitativa y cuantitativamente, grandes esfuerzos estratégicos.

- PROYECCION: se otorga valor [1] cuando el país lidera un Grupo de Combate, porque ello no solo implica que este tiene capacidades suficientes como para coordinar el planeamiento, despliegue y sostenimiento de esta fuerza multinacional y demuestra la voluntad política para proporcionar capacidades militares a la UE, sino que también constituye una de las precondiciones para participar en la Cooperación Estructurada Permanente. El valor [0] especifica países que no lideran dichas fuerzas. Esta condición opta por una asignación de valores dicotómicos por la naturaleza conceptual de la misma. 


\section{RESULTADOS}

\section{CONDICIONES NECESARIAS Y SUFICIENTES PARA LOS PAÍSES LÍDERES}

El análisis de condiciones necesarias explicativas de los países líderes en materia de defensa europea refleja que, de entre las seis condiciones evaluadas, solamente dos de ellas cumplen con los requisitos metodológicos para verificar su consistencia al alcanzar una puntuación superior a 0,9 (Schneider y Wagemann, 2012: 143). Recordemos que una condición necesaria debe estar presente para que ocurra el outcome, pero su presencia no garantiza dicha ocurrencia (Ragin, 2009: 109). El significado práctico de ello, tal y como se observa en la tabla 3, es que la mayoría de los países líderes no pertenecen geográficamente al este de Europa (de hecho, son antiguas potencias del bloque occidental que formaban parte de la OTAN durante la Guerra Fría, y por lo tanto con una cultura estratégica distinta que la existente entre los países neutrales u orientales) y lideran algún Grupo de Combate. Interpretaciones más laxas del valor mínimo requerido para condiciones necesarias llevarían a considerar que EJERCITO $(0,815603)$ y ESTRATEGIA $(0,834043)$ están siempre presentes en el caso de países líderes. Sin embargo, la matriz de datos demuestra que Suecia no cuenta con un ejército muy numeroso, por ejemplo, y que Italia ha descuidado elaborar una estrategia de seguridad similar a la de otros países estrategas o globalistas.

Tabla 3. Análisis de condiciones necesarias. Outcome: liderazgo

\begin{tabular}{lcl}
\hline \multicolumn{1}{c}{ Condiciones } & Consistencia & Cobertura \\
\hline este & 0.072340 & 0.051000 \\
\hline - este & 0.927660 & 0.436000 \\
\hline alianzas & 0.770213 & 0.781295 \\
\hline -alianzas & 0.248227 & 0.096953 \\
\hline presupuesto & 0.693617 & 0.958824 \\
\hline -presupuesto & 0.387234 & 0.137186 \\
\hline ejercito & 0.815603 & 0.713399 \\
\hline - ejercito & 0.218440 & 0.090909 \\
\hline estrategia & 0.834043 & 0.468526 \\
\hline - estrategia & 0.245390 & 0.138956 \\
\hline proyeccion & 0.924823 & 0.652000 \\
\hline - proyeccion & 0.075177 & 0.035333 \\
\hline
\end{tabular}

Fuente: Elaboración propia. 
No obstante, el análisis de condiciones necesarias debe ser complementado con el análisis de condiciones suficientes (tabla 4). Este busca condiciones individuales que no son suficientes por sí mismas, pero que necesitan ser combinadas con otras para que ocurra el outcome. Este razonamiento está basado en la existencia de condiciones INUS que son «insuficientes aunque parte necesaria de una condición que es innecesaria aunque suficiente para la ocurrencia del resultado». Además, el análisis de condiciones suficientes aboga por la equifinalidad, que no es más que la posibilidad de encontrar diversas combinaciones de condiciones suficientes que conduzcan al resultado.

Tabla 4. Análisis de condiciones suficientes.

Solución intermedia. Outcome: liderazgo

\begin{tabular}{|c|c|c|c|c|}
\hline & $\begin{array}{c}\text { Cobertura } \\
\text { bruta }\end{array}$ & $\begin{array}{l}\text { Cobertura } \\
\text { única }\end{array}$ & Consistencia & Casos \\
\hline $\begin{array}{l}\text { proyeccion } \\
\text { *estrategia* } \\
\text { - este }\end{array}$ & 0.687943 & 0.202837 & 0.989796 & $\begin{array}{l}\text { Francia }(1,1) \text {, Suecia } \\
(1,0.95) \text {, UK }(1,1) \text {, } \\
\text { Alemania }(0.95,1) \text {, } \\
\text { España }(0.95,1)\end{array}$ \\
\hline $\begin{array}{l}\text { proyeccion } \\
\text { *ejercito* }^{*} \\
\text { presupuesto } \\
\text { *alianzas*_este }^{*}\end{array}$ & 0.604255 & 0.119149 & 0.997658 & $\begin{array}{l}\text { Francia }(0.99,1), \\
\text { Alemania }(0.95,1), \text { UK } \\
(0.95,1) \text {, Italia }(0.83,1) \text {, } \\
\text { España }(0.53,1)\end{array}$ \\
\hline
\end{tabular}

Cobertura de la solución: 0.807092; consistencia de la solución: 0.989565; frecuencia de corte: 1.000000; Consistencia de corte: 0.989474 . Modelo: liderazgo $=\mathrm{f}$ (proyeccion, estrategia, ejercito, presupuesto, alianzas, este).

Expectativas direccionales: proyeccion (presente), estrategia (presente), ejercito (presente), presupuesto (presente), alianzas (presente), - este (ausente).

Fuente: Elaboración propia.

Nuestro análisis demuestra que existen dos posibles rutas para llegar a ser un líder. Por un lado, se observa un tipo de liderazgo caracterizado por países de Europa Occidental ( - este) que lideran algún Grupo de Combate y que cuentan con una estrategia de seguridad global o estratégica. Este liderazgo cubre casi un $70 \%$ de los países líderes, aunque solamente un $20 \%$ de ellos pueden explicarse exclusivamente de esta forma. La alternativa a esta ruta es más exigente porque requiere una combinación más numerosa de condiciones. Países de Europa Occidental con proyección, un ejército bien dotado, un sólido presupuesto de defensa y bien integrados en redes de cooperación 
europeas. Aunque el porcentaje de casos positivos exclusivamente explicados por esta ruta es muy reducido (apenas un $12 \%$ ), un $60 \%$ de los casos podrían explicarse bajo este patrón.

Con mayor detalle, la expresión proyeccion*estrategia* ${ }^{*}$ este muestra que Francia, Reino Unido, Suecia, España y Alemania poseen estrategias de seguridad que codifican sus intereses y pueden participar en la Cooperación Estructurada Permanente. Además de las dos potencias militares europeas - Gran Bretaña y Francia - que disponen de sendos asientos permanentes en el Consejo de Seguridad de las Naciones Unidas, son poderes nucleares, mantienen una importante presencia militar permanente fuera de su territorio nacional y poseen fuerzas expedicionarias (aunque la capacidad de proyección británica se ha visto reducida tras la retirada de sus últimos cruceros de cubierta corrida y a la espera de la entrada en servicio de los nuevos portaaviones); los tres países restantes también forman parte de este grupo que podría liderar la defensa europea. Mientras Alemania ha mantenido históricamente una posición secundaria en esta materia debido a su legado histórico, es una firme defensora de las iniciativas europeas, lidera dos Grupos de Combate y ha definido - no sin controversias domésticas - sus objetivos de política exterior. Además, dispone de una moderna industria de defensa y un poderoso ejército proyectable por vía aérea. Por su parte, España cumple con los condicionantes intermedios del liderazgo, siendo especialmente relevante la posesión de una notable capacidad expedicionaria que se verá reforzada con el buque de asalto anfibio L-61 Juan Carlos y los aviones de transporte A-400M. Finalmente, a pesar de su neutralidad, Suecia no solo es una firme partidaria de la defensa europea en su dimensión civil y militar, sino que también dispone de una magnífica industria de defensa capaz de construir sofisticados sistemas de manera autónoma y posee importantes capacidades de proyección aérea. Paradójicamente, a pesar de que Italia posee un importante tejido empresarial, participa en múltiples fuerzas combinadas europeas, dispone de medios de proyección aero-naval (es uno de los pocos países europeos que posee portaaeronaves y buques de asalto anfibio) y podría participar en la Cooperación Estructurada Permanente, al no disponer de una estrategia de seguridad que codifique sus intereses en el mundo la aparta de este grupo.

No obstante, usando la expresión proyeccion*ejercito* presupuesto *alianzas* ${ }^{*}$ este observamos dos pequeños cambios. Mientras Suecia desaparece de esta lista debido a la reducida entidad de su ejército y limitada participación en otras estructuras además de los Grupos de Combate e iniciativas como la EDA, Italia aparece precisamente por la posesión de estos valores (el volumen de sus ejércitos, su presupuesto de defensa y su colaboración en otras iniciativas militares europeas). 


\section{CONDICIONES NECESARIAS Y SUFICIENTES PARA PAÍSES QUE NO MUESTRAN LIDERAZGO}

Una vez examinados los países líderes, ¿qué caracteriza a los países que van a remolque de ellos? El análisis de las condiciones necesarias, recogido en la tabla 5, identifica dos elementos que la mayoría de ellos comparten: no participan en las principales redes de cooperación en defensa y poseen un presupuesto militar limitado. Sin llegar a ser exigentes con el umbral de consistencia, podríamos admitir que estos países también carecen de unos ejércitos modernos y capaces. En cualquier caso, esto vendría explicado por la falta de presupuesto y por no tener la exigencia de aportar efectivos a las misiones derivadas de la pertenencia a redes cooperativas. Así, podemos asegurar que el factor geográfico no es determinante en este caso, como parecía serlo para los países líderes, como tampoco lo es la ausencia de liderazgo en Grupos de Combate, justamente porque vemos que países como Portugal, Polonia o Grecia asumen este tipo de compromisos.

Tabla 5. Análisis de condiciones necesarias. Outcome: -liderazgo

\begin{tabular}{lcl}
\hline \multicolumn{1}{c}{ Condiciones } & Consistencia & Cobertura \\
\hline este & 0.528691 & 0.949000 \\
\hline - este & 0.471309 & 0.564000 \\
\hline alianzas & 0.091922 & 0.237410 \\
\hline - alianzas & 0.915320 & 0.910249 \\
\hline presupuesto & 0.043454 & 0.152941 \\
\hline -presupuesto & 0.988301 & 0.891457 \\
\hline ejercito & 0.142061 & 0.316377 \\
\hline - ejercito & 0.871309 & 0.923259 \\
\hline estrategia & 0.402786 & 0.576096 \\
\hline - estrategia & 0.628412 & 0.906024 \\
\hline proyeccion & 0.193872 & 0.348000 \\
\hline -proyeccion & 0.806128 & 0.964667 \\
\hline
\end{tabular}

Fuente: Elaboración propia.

En cualquier caso, atendiendo a los resultados del análisis de condiciones suficientes recogidos en la tabla 6 , que un país sea poco proclive a liderar la defensa europea puede explicarse de cuatro formas diferentes. 
Tabla 6. Análisis de condiciones suficientes.

Solución intermedia. Outcome: -liderazgo

\begin{tabular}{|c|c|c|c|c|}
\hline & $\begin{array}{c}\text { Cobertura } \\
\text { bruta }\end{array}$ & $\begin{array}{l}\text { Cobertura } \\
\text { única }\end{array}$ & Consistencia & Casos \\
\hline $\begin{array}{l}\text { - estrategia* } \\
\text { - presupuesto* } \\
\text { - alianzas }\end{array}$ & 0.573816 & 0.167131 & 0.990385 & $\begin{array}{l}\text { Grecia }(0.97,0.95), \\
\text { Austria }(0.95,1), \text { Irlandia } \\
(0.95,1), \text { Luxemburgo } \\
(0.95,0.99), \text { Malta } \\
(0.95,1), \text { Portugal } \\
(0.95,0.99), \text { Rumania } \\
(0.95,1), \text { Eslovaquia } \\
(0.95,1)\end{array}$ \\
\hline $\begin{array}{l}\text { - proyeccion* } \\
\text { - ejercito* } \\
\text {-presupuesto* } \\
\text { - alianzas }\end{array}$ & 0.679666 & 0.059610 & 1.000000 & $\begin{array}{l}\text { Estonia }(0.99,1) \text {, Hungría } \\
(0.99,1) \text {, Irlanda }(0.99,1) \text {, } \\
\text { Letonia }(0.99,1) \text {, Lituania } \\
(0.99,1) \text {, Malta }(0.99,1) \text {, } \\
\text { Eslovaquia }(0.99,1), \\
\text { Eslovenia }(0.99,1) \text {, } \\
\text { Austria }(0.97,1) \text {, Bulgaria } \\
(0.97,1) \text {, Finlandia } \\
(0.97,0.99) \text {, Luxemburgo } \\
(0.95,0.99)\end{array}$ \\
\hline $\begin{array}{l}\text { - proyeccion* } \\
\text { - estrategia* } \\
\text { - ejercito* } \\
\text { - presupuesto }\end{array}$ & 0.455153 & 0.050139 & 1.000000 & $\begin{array}{l}\text { Austria }(0.95,1), \text { Bélgica } \\
(0.95,0.99), \text { Irlanda } \\
(0.95,1), \text { Luxemburgo } \\
(0.95,0.99), \text { Malta } \\
(0.95,1), \text { Eslovaquia } \\
(0.95,1)\end{array}$ \\
\hline $\begin{array}{l}\text { - ejercito* } \\
\text { - presupuesto* } \\
\text { - alianzas*este }\end{array}$ & 0.458496 & 0.054039 & 1.000000 & $\begin{array}{l}\text { Estonia }(0.99,1), \text { Hungría } \\
(0.99,1) \text {, Letonia }(0.99,1) \text {, } \\
\text { Lituania }(0.99,1), \\
\text { Eslovaquia }(0.99,1), \\
\text { Eslovenia }(0.99,1), \\
\text { Bulgaria }(0.97,1), \text { Rep. } \\
\text { Checa }(0.97,0.99)\end{array}$ \\
\hline
\end{tabular}

Cobertura de la solución: 0.952646; consistencia de la solución: 0.994186; frecuencia de corte 1.000000; Consistencia de corte: 0.910714 . Modelo: - liderazgo $=\mathrm{f}($ proyeccion, estrategia, ejercito, presupuesto, alianzas, este).

Expectativas direccionales: - proyeccion (ausente), - estrategia (ausente), - ejercito (ausente), -presupuesto (ausente), -alianzas (ausente), este (presente).

Fuente: Elaboración propia. 
Como era de esperar, el rasgo más característico de estas rutas es la negación de la condición (expresado con la tilde $\sim$ ), entendiendo por ello que estos países no son estratégicamente avanzados, no cuentan con presupuestos sólidos o están en la periferia de las redes de cooperación. En cualquier caso, una primera forma de no ser un líder se explica por la expresión $\sim$ estrategia* ${ }^{*}$ presupuesto*-alianzas, que es completamente coherente con la noción de países sin liderazgo y por ello explicaría casi el $60 \%$ de los casos. No obstante, llama la atención Grecia, que, con un notable gasto en defensa a pesar de su precaria situación económica y unas importantes fuerzas armadas diseñadas, organizadas y equipadas para disuadir a Turquía, ni posee una estrategia de seguridad que codifique sus intereses ni tampoco participa en otras iniciativas europeas.

Una segunda vía permite capturar la combinación de cuatro condiciones: países que no lideran Grupos de Combate, no tienen un ejército bien dotado, no destinan grandes recursos a la defensa y no están integrados en redes de cooperación. Esta combinación de condiciones cubre el $67 \%$ de los casos, entre los que se hallan tres países con larga tradición neutralista como Austria, Irlanda y Finlandia.

La tercera vía vuelve a incidir en la ausencia de liderazgo en Grupos de Combate, un ejército poderoso y un presupuesto generoso, a las que cabe añadir la ausencia de una estrategia de seguridad ambiciosa ${ }^{7}$. La última vía se refiere a los países de Europa del Este que no cuentan con un ejército numeroso y que tampoco destinan grandes partidas de gasto a defensa ni están integrados en redes europeas de cooperación dominadas por los países de Europa Occidental.

\section{CONCLUSIONES}

Desde el lanzamiento de la PESD hasta la configuración de la PCSD, la $\mathrm{UE}$ ha realizado enormes progresos en defensa. Aunque estos no han logrado dotar a Bruselas de «una capacidad autónoma basada en fuerzas militares creíbles» como pretendían Londres y París en Saint Malo, dichos avances parecían impensables en 1999.

En dieciséis años Bruselas se ha dotado de una estrategia de seguridad, definido un catálogo de misiones y desarrollado capacidades para satisfacerlas,

7 El análisis de condiciones suficientes permite detectar una condición necesaria oculta, es decir, condiciones que no aparecen en todas las rutas, en nuestro caso - alianzas, pero que alcanzan una puntuación de consistencia muy alta en el análisis de condiciones necesarias. Esta situación se produce, en la mayoría de los casos, por la influencia de casos contrafácticos en el proceso de minimización. 
creado los órganos necesarios para conducir las operaciones, concretado mecanismos de cooperación en defensa, fijado estándares comunes en armamento, desarrollado fuerzas multinacionales para la gestión de crisis, realizado varias intervenciones exteriores y sentado las bases para crear una defensa común. No obstante, estos logros formales no se han traducido en estrategias coherentes, capacidades creíbles, estructuras operativas o intervenciones relevantes; y tampoco parece probable que esta situación varíe en el corto plazo.

Precisamente, este desfase entre las expectativas generadas por los líderes europeos y la realidad observada en el día a día ha sido un rasgo distintivo de la defensa europea desde sus inicios. La PESD culminó sin haber alcanzado los objetivos de capacidades previstos, desplegado sus fuerzas de vanguardia ni conducido ninguna misión relevante; y la PCSD se halla paralizada a pesar de los ambiciosos planteamientos contenidos en el Tratado de Lisboa para avanzar hacia una defensa común. No obstante, cualquier desarrollo en esta materia quedará condicionado a la superación de numerosas contradicciones de difícil solución, como la supeditación práctica a la OTAN, la presencia de culturas estratégicas incompatibles, la inexistencia de un mínimo común denominador sobre el significado de la PCSD, el mantenimiento de intereses estratégicos e industriales opuestos, la carencia crónica de capacidades militares, la mejorable gestión de los recursos de defensa o, tal y como ha intentado mostrar el artículo, la ausencia de un liderazgo claro en esta materia.

De hecho, podríamos plantear que existen dos grandes modos de liderar el desarrollo de la PCSD: uno de tipo identitario que recoge los postulados constructivistas (países de Europa Occidental que lideran algún Grupo de Combate y disponen de una estrategia de seguridad consolidada como Francia, Reino Unido, Suecia, España o Alemania) y otro más militarista que adopta los principios realistas (países de Europa Occidental con un ejército bien dotado, un sólido presupuesto de defensa, capacidad para proyectar su poder e integrados en las redes de cooperación europeas como Francia, Reino Unido, España, Alemania o Italia). No obstante, la falta de liderazgo se explica precisamente por la carencia de capacidades militares, puesto que sus factores determinantes son el reducido gasto en defensa, la posesión de ejércitos pequeños y poco operativos y la no participación — posiblemente debido a los condicionantes anteriores - en iniciativas de cooperación militar europeas. En cualquier caso, un país escasamente proclive a asumir el liderazgo puede ser explicado de cuatro formas diferentes, todas ellas determinadas por la falta de capacidades:

- Un limitado gasto en defensa junto con la carencia de una estrategia de seguridad y la no participación en iniciativas de cooperación específicas. 
- Unos ejércitos mal equipados y un reducido gasto en defensa junto con la no participación en redes de cooperación ni el liderazgo de un Grupo de Combate.

- Los factores arriba mencionados más la carencia de una estrategia de seguridad ambiciosa.

- Países de Europa del Este con ejércitos pequeños y mal equipados, un reducido gasto en defensa y no integrados en las estructuras de defensa.

Y es que la voluntad política sin las capacidades militares que la sustenten difuminan su liderazgo, comprometen su desarrollo y restan credibilidad a los compromisos adquiridos, tal y como hemos observado desde 1999 con la construcción de una compleja arquitectura de defensa europea hueca de capacidades e incapaz de satisfacer los retos de seguridad que han surgido desde entonces. Igualmente, la posesión de medios materiales sin la determinación política para ponerlos al servicio de la PCSD también compromete la viabilidad de la defensa europea, tal y como revela la carencia crónica de capacidades a pesar de los objetivos militares trazados por Bruselas y los compromisos adquiridos por los gobiernos; o la inexistencia de ninguna Cooperación Estructurada Permanente — con unas laxas exigencias de colaboración- susceptibles de avanzar en la defensa europea a dos velocidades. Ello nos lleva a reflexionar sobre el latente bandwagoning que existe en esta materia, puesto que muchos países europeos promueven el desarrollo de la PCSD — bien de forma autónoma en su doble vertiente civil-militar como en complementariedad con la OTAN_ pero ni le dotan de contenido ni tampoco contribuyen con capacidades.

No obstante, una reflexión similar también puede aplicarse al caso de la Alianza Atlántica, puesto que varios países - especialmente los menos dotados militarmente, con una latente percepción de inseguridad provocada por la asertividad rusa y con un complejo dilema de seguridad - tienen una gran voluntad política en el mantenimiento de esta organización pero carecen de las capacidades para apoyar su transformación militar, adoptando así una postura de bandwagoning en relación al liderazgo norteamericano.

En otras palabras, no se debería caer en el error constructivista y asumir que la bruselización de la seguridad europea motivará la consolidación de una política de defensa susceptible de culminar en una defensa común. No solo debe desarrollarse una voluntad política y una cultura estratégica común que podrían consolidarse por socialización —aunque no podemos descartar que la voluntad esté motivada por el interés nacional y la solución más racional al dilema de seguridad de cada país - sino que también es necesario disponer de capacidades militares. Solo de esta forma los países europeos podrán observar los beneficios que la defensa común tiene tanto para su propia seguridad como 
para su específico interés nacional, resolviendo así su dilema de seguridad a favor de la UE en detrimento de otras opciones estratégicas.

Una de las razones tradicionalmente esgrimidas para impulsar la defensa europea es que los Estados ya no pueden resolver su dilema de seguridad individualmente y hoy se argumenta que la crisis económica requiere poner en común los recursos de defensa nacionales para minimizar la pérdida de capacidades militares. Sin embargo, entre la bruselización de las políticas de defensa nacionales, como sostienen los constructivistas, o la imposible cooperación militar, como creen los (neo)realistas, se halla una realidad que nos muestra que todavía queda mucho tiempo para que la UE pueda desarrollar una defensa común y realizar estas funciones con mayor eficacia que los Estados y mayor disuasión que la Alianza Atlántica.

\section{Bibliografía}

Biehl, H., Giegerich, B. y Jonas, A. (2013). Strategic Cultures in Europe: Security and Defence Policies Across the Continent. Berlin: Springer. Disponible en: https://doi. org/10.1007/978-3-658-01168-0.

Biscop, S. (2014). The Summit of Our Ambition? European Defence between Brussels and Wales.

Security Policy Brief, 55, 1-6. Disponible en: http://egmontinstitute.be/wp-content/ uploads/2014/03/SPB55-Summit-of-our-Ambition.pdf.

Breuer, F. (2010). Between Intergovernmentalism and socialisation: the Brusselization of ESDP. Firenze: European University Institute.

Cornish, P. y Edwards, G. (2001). Beyond the EU/NATO Dichotomy. International Affairs, 77 (3), 587-603. Disponible en: https://doi.org/10.1111/1468-2346.00208.

De France, O. y Witney, N. (2013). Europe's Strategic Cacophony. Bruxelles: ECFR.

Directorate-General for External Policies (2011). The impact of the financial crisis on European defence. Bruxelles: Parlamento Europeo.

Dyson, T. (2013). Balancing Threat, Not Capabilities: European Defence Cooperation as Reformed Bandwagoning. Contemporary Security Policy, 34 (2), 387-391. Disponible en: https://doi.org/10.1080/13523260.2013.808073.

Eilstrup, M. (2014). Europe's Defence Dilemma. The International Spectator, 49 (2), 83-116. Disponible en: https://doi.org/10.1080/03932729.2014.910728.

European Defence Agency (2013). Defence Data 2012. Bruxelles: EDA.

- (2014a). National Defence Data 2012 of the EDA participating Member States. Bruxelles: EDA.

- (2014b). Annual Report 2013. Bruxelles: EDA.

Fatjó, P. y Colom, G. (2005). La defensa de la Unión Europea: voluntades politicas y capacidades militares básicas. Barcelona: CIDOB.

Fu-Chang, Ch. (2011). European Defence Agency. Motor of Strengthening the EU's Military Capabilities? European Foreign Affairs Review, 16 (1), 59-87.

Glaser, Ch. (1995). Realists as optimists: Cooperation as self-help. International Security, 19 (3), 50-90. Disponible en: https://doi.org/10.2307/2539079. 
Grevi, G., Helly, D. y Keohane, D. (eds.) (2009). European Security and Defence: the first 10 years. Paris: ISS-EU.

Helwig, N. (2014). The High Representative 3.0. Helsinki: FIIA.

Herz, J. (1951). Political Realism and Political Idealism. London: Cambridge University Press.

Jervis, R. (1978). Cooperation under the Security Dilemma. World Politics, 30 (2), 167-214. Disponible en: https://doi.org/10.2307/2009958.

Johnston, A. (1995). Thinking about Strategic Culture. International Security, 19 (4), 33-64. Disponible en: https://doi.org/10.2307/2539119.

Larsen, H. (2014). NATO, EU and Russia after 2014: Great Power Politics and the Ukrainian crisis. Copenhagen: DIIS.

Longhurst, K. (2000). The Concept of Strategic Culture. En G. Kummel y A. D. Prüfert (eds.). Military Sociology: the Richness of a Discipline (pp. 301-310). BadenBaden: Nomos.

Marx, A., Cambré, B. y Rihoux, B. (2013). Crisp-Set Qualitative Comparative Analysis in Organizational Studies. En P. C. Fiss, B. Cambré y A. Marx (eds.). Configurational Theory and Methods in Organizational Research (pp. 23-47). Bingley: Emerald. Disponible en: https://doi.org/10.1108/S0733-558X(2013)0000038006.

— y Dusa, A. (2011). Crisp-Set Qualitative Comparative Analysis (csQCA), Contradictions and Consistency Benchmarks for Model Specification. Methodological Innovations Online, 6 (2), 103-148. Disponible en: https://doi.org/10.4256/mio.2010.0037.

Meyer, Ch. (2005). Convergence Towards a European Strategic Culture? A Constructivist Framework for Explaining Changing Norms. European Journal of International Relations, 11 (4), 523-549. Disponible en: https://doi.org/10.1177/1354066105057899.

Pohl, B. (2013). Neither Bandwagoning nor Balancing: Explaining Europe's Security Policy. Contemporary Security Policy, 34 (2), 353-373. Disponible en: https://doi.org/10.1080/ 13523260.2013 .805932$.

Posen, B. (2006). European Union Security and Defense Policy: Response to Unipolarity? Security Studies, 15 (2), 149-186. Disponible en: https://doi.org/10.1080/0963641 0600829356.

Ragin, Ch. (1987). The Comparative Method: Moving Beyond Quantitative and Qualitative Strategies. Berkeley: University of California Press.

- (2000). Fuzzy-Set Social Science. Chicago: University of Chicago Press.

- (2008). Redesigning Social Inquiry: Fuzzy Sets and Beyond. Chicago: University of Chicago Press.

Rogers, J. (2009). From 'Civilian Power' to 'Global Power': Explicating the European Union's 'Grand Strategy' though the Articulation of Discourse Theory. Journal of Common Market Studies, 47 (4), 831-862. Disponible en: https://doi.org/10.1111/j.1468-5965. 2009.02007.x.

Rynning, S. (2011). Realism and the Common European Security and Defence Policy. Journal ofCommon MarketStudies, 49 (1), 23-42. Disponible en: https://doi.org/10.1111/j.14685965.2010.02127.x.

Schneider, C. y Wagemann, C. (2012). Set-Theoric Methods for the Social Sciences. Cambridge: Cambridge University Press. Disponible en: https://doi.org/10.1017/CBO978113900 4244. 
Toje, A. (2008). The consensus-expectations gap: explaining Europe's ineffective foreign policy. Security Dialogue, 39 (1), 121-141. Disponible en: https://doi. org/10.1177/0967010607086826.

Trybus, M. (2014). Buying Defence and Security in Europe. New York: Cambridge University Press. Disponible en: https://doi.org/10.1017/CBO9780511751462.

Witney, N. (2008). Re-energising Europe's security and defence policy. London: ECFR.

Zadeh, L. (1965). Fuzzy sets. Information and Control, 8, 338-353. Disponible en: https://doi. org/10.1016/S0019-9958(65)90241-X. 